\title{
The value and the need of nature-based solutions for resilient urban ecosystems: from citizen engagement to novel Nexus perspectives for fair and safe use and development of natural and urban resources Insights from the city of Rome (Italy) water resource and risk management programs
}

\author{
Fernando NARDI, Water Resources Research and Documentation Center, University for Foreigners of \\ Perugia, Italy \\ Andrea SPASIANO, Water Resources Research and Documentation Center, University for Foreigners of \\ Perugia, Italy \\ Umberto BARTOCCINI, Water Resources Research and Documentation Center, University for Foreigners of \\ Perugia, Italy \\ Antonio ANNIS, Water Resources Research and Documentation Center, University for Foreigners of \\ Perugia, Italy
}

\begin{abstract}
The three million inhabitants of the city of Rome are mostly unaware of the significant hydrological and meteorological risks affecting the urban ecosystems. Floods, droughts, landslides, sinkholes as well as urban and industrial pressures impacting the safety and sustainability of natural and human resources. The city, following a significant urban and demographic growth of the last 50 years, is still one of the largest agricultural metropolises in the world. Fair and safe access to water, food, energy and environmental resources is no longer a mere optimization challenge (i.e., given for granted), but a real (and actually pressing) urban and land development challenge. Decision makers are prompted to take important actions and design a medium to long term vision to guarantee (preserve) the abundance of resources that gave birth to one of the wealthiest early civilizations in the world.

Competing and often conflicting economic sectors uncertainties, driven by social and climate change, and lack of financial resources to cover all needs and mitigate all natural and human-driven hazard characterize a multi-risk multi-actor multi-sector grand challenge for the City of Rome. This challenging framework is not merely a technical challenge, but several diverse factors increase the complexity from multiple perspectives (governance and policy, human behaviour, social and cultural etc.). The European Green Deal is providing an integrated framework where long time existing policies and technical regulations on safe and sustainable natural and urban planning (Water Framework, Biodiversity, Circular economy, Blue Growth Directives, etc.) are joining efforts under one umbrella embracing green and blue principles. Nature based solutions offer multiple advantages, but the transition from grey infrastructure and engineering towards green and blue growths is facing several technical and cultural challenges. This contribution presents experiences, issues, insights derived from recent and ongoing scientific and applied research projects and urban development projects for the city of Rome with specific regard to water resource and risk management programs and interlinked landscape planning actions. Among the interlinkages and multi-disciplinary feedbacks, the water-human, water-food and the extended water-food-ecosystem nexus dynamics are investigated and presented at the conceptual level. Specific interest and focus of this work are the value and the need of preserving and further developing green, blue spaces as well the significant
\end{abstract}


natural and cultural heritage that characterize the city of Rome. Further foci are linked to the cultural, social and economic value of also preserving the agricultural footprint of the extended metropolitan region of Rome (and Lazio region). The presented case study shows the importance of enlarging and interfacing the perspectives while implemented the European Green Deal at the urban level testing both bottom-up and top-down approaches, investigating the optimal governance dynamics that shall be implemented for successful embracing of water and blue actions. A wide range of components, methods, procedures that govern safe and sustainable urban planning are presented from citizen engagement to urban and engineering design for identifying and fostering the most suitable actions that would promote resilience and safety of complex urban setting, like the selected city of Rome case study.

\section{Keywords}

Nature based solutions, Water resources, Risk mitigation, Citizen engagement, Water Energy Food Ecosystem Nexus, urban planning

\section{Introduction}

The early civilization, that gave birth to the Roman Empire more than 2,000 years ago, was initiated and grow thanks to the abundance of natural resources that characterize the original urban domain that is Tiber River floodplain. The city of Rome was born and developed along the Tiber fluvial system with first urban settlements that developed along the riparian areas and surrounding landscape (i.e. the seven hills of Rome). The rapid population and economic growth of the Roman empire was sustained by the large availability of water resources and fertile lands. The knowledge and technological advancements achieved by the Romans on water resource management was key for fostering a wealth and safe human settlement. More than 1 million of inhabitants occupied the original city domain. The Roman mastering in designing, engineering and realization of aqueducts and sewer systems, still visible today, was a cornerstone of the roman empire's growth.

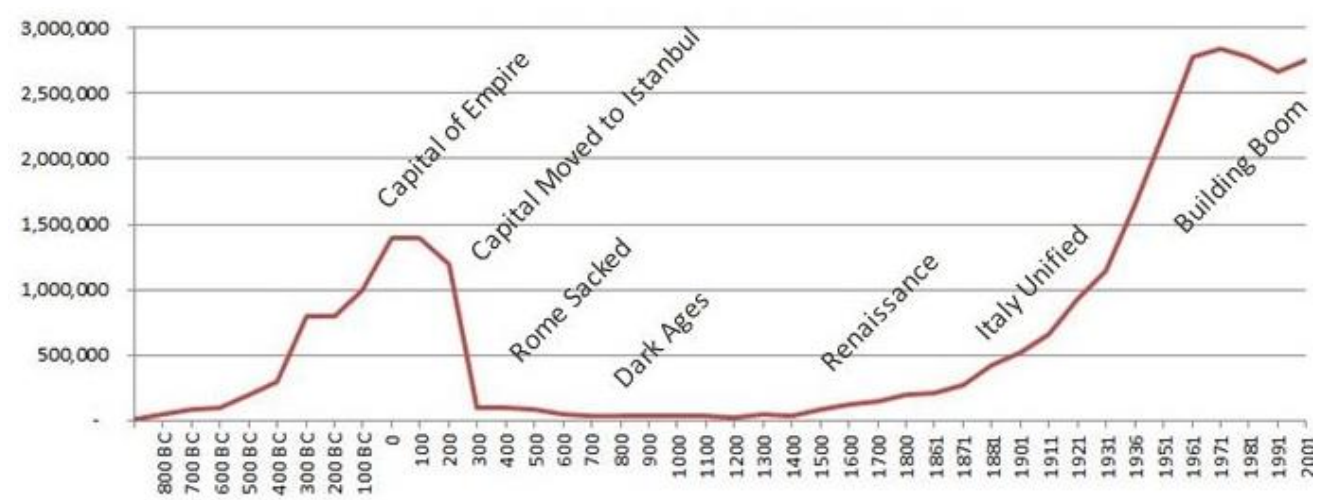

Figure 1. The population of the city of Rome. Source(s): Harl, 1998; Italian National Institute of Statistics, 2013; Comune di Roma, 2013; Twine, 1992; elaborated by Rachel Comte, The Spatial Evolution of Rome.

The Rome population, following the sharp decrease that follow the Empire's and the dark times of Middle Age, started to slowly increase during the Renaissance, and then grow considerably in the last two centuries (Figure 1). In particular, after Italy unified, and more importantly after World War II, a rapid growth occurred in the last 50-70 years during the so-called "building boom". A remarkable portion of the Italian population now lives in Rome that, to date, hosts more than 2,500,000 inhabitants. The city of Rome urban development process was not properly supported by consistent and distributed knowledge and protection of natural and 
cultural resources. Intense urban growth and sprawl occurred without proper consideration of ecologic, hydrologic, geomorphic processes and features that means without considering the environmental ecosystem value of riverine vegetated systems along low laying areas and forested areas on the hillslopes as well as the related hydro-geomorphic natural hazards (i.e. floods and landslides).

The urban and land human-induced change also occurred towards the coast. The Rome coastal area, originally characterized by a transition low laying wetland area with predominant presence of swamps, was the subject of a land reclamation interventions in the first half of the XX century to support agricultural activities. The so-called "Halley's comet" urban transformations was implemented connecting the city to the land-reclaimed coastal zone. The coastal area is still the subject of economic development sectors with further human interventions that are transforming the area in an important urban and infrastructure development hub. The area is still predominantly devoted to agricultural activity, but the major road and airport infrastructures (e.g. the Fiumicino national airport) are further supporting the expansion of cities of Ostia and Fiumicino and surrounding commercial and logistics centers. To note that, along the Tiber River, especially along the historical coastal line, a significant presence of archaeological assets was found in the area of "Ancient Ostia" where historical settlements from the Roman empire show the importance of this area as coastal harbour and fluvial transportation line connected to the Rome Forum area in the actual city center. The entire coastal area is also subject to a high-level flood and subsidence risk with inefficient drainage system that is not able to safely drain intense rainfall events. Moreover, water use along the coast is creating significant issue of salinity intrusion, land subsidence and water quality (See Figure 2).

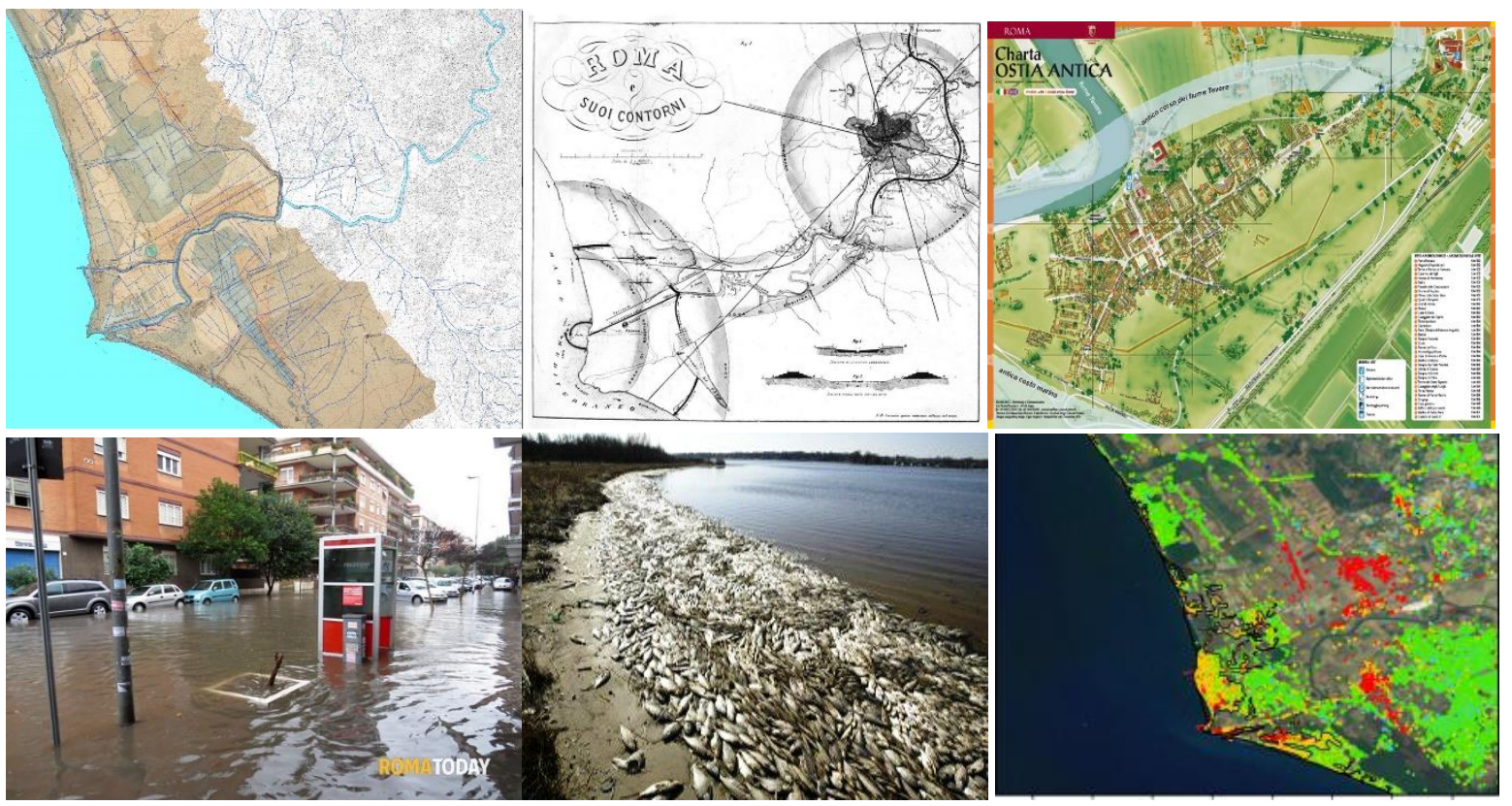

Figure 2. The coastal area of the Rome metropolis: a) the original coastal line and the original swamps; $b$ ) the Halley's Comet urban planning vision connecting Rome center to the coast; c) the Ancient Ostia archeological footprint along the coastal/fluvial Tiber River floodplain; d) Floods in coastal settlements of Piana del Sole; water quality and pollution problems in the area; The subsidence issue affecting the coast.

Only in recent times, in the last 20-30 years, the city urban master plan started to properly integrate with the newly created water resource and risk management plans. The regional and river basin scale territorial landscape management plans (namely the Piano Territoriale Paesaggistico Regionale - PTPR), in the last few years, incorporated the knowledge and risk mitigation actions, of the Tiber/Rome flood risk management and mapping plans (i.e. namely the Piano di Assetto Idrogeologico - PAl, the flood and landslide zoning and 
regional planning) by the Tiber River Basin Authority that also include mapping and protection measures for the secondary and minor tributaries, the riparian corridors. As a result, PTPR and PAI, only in the last 10 years are able to jointly provide a proper eco-hydro-geomorphic zoning, mapping and regional planning to value and protect the ecologic and hydrologic value of blue and green spaces of the Rome metropolis.

To note that the city of Rome, notwithstanding the intense and distributed urbanization, is still predominantly occupied by agricultural areas. At present, Rome, with its $50 \%$ of areas devoted to agriculture is the largest agri-metropolis in Europe and one of the largest in the world (Figure 3).

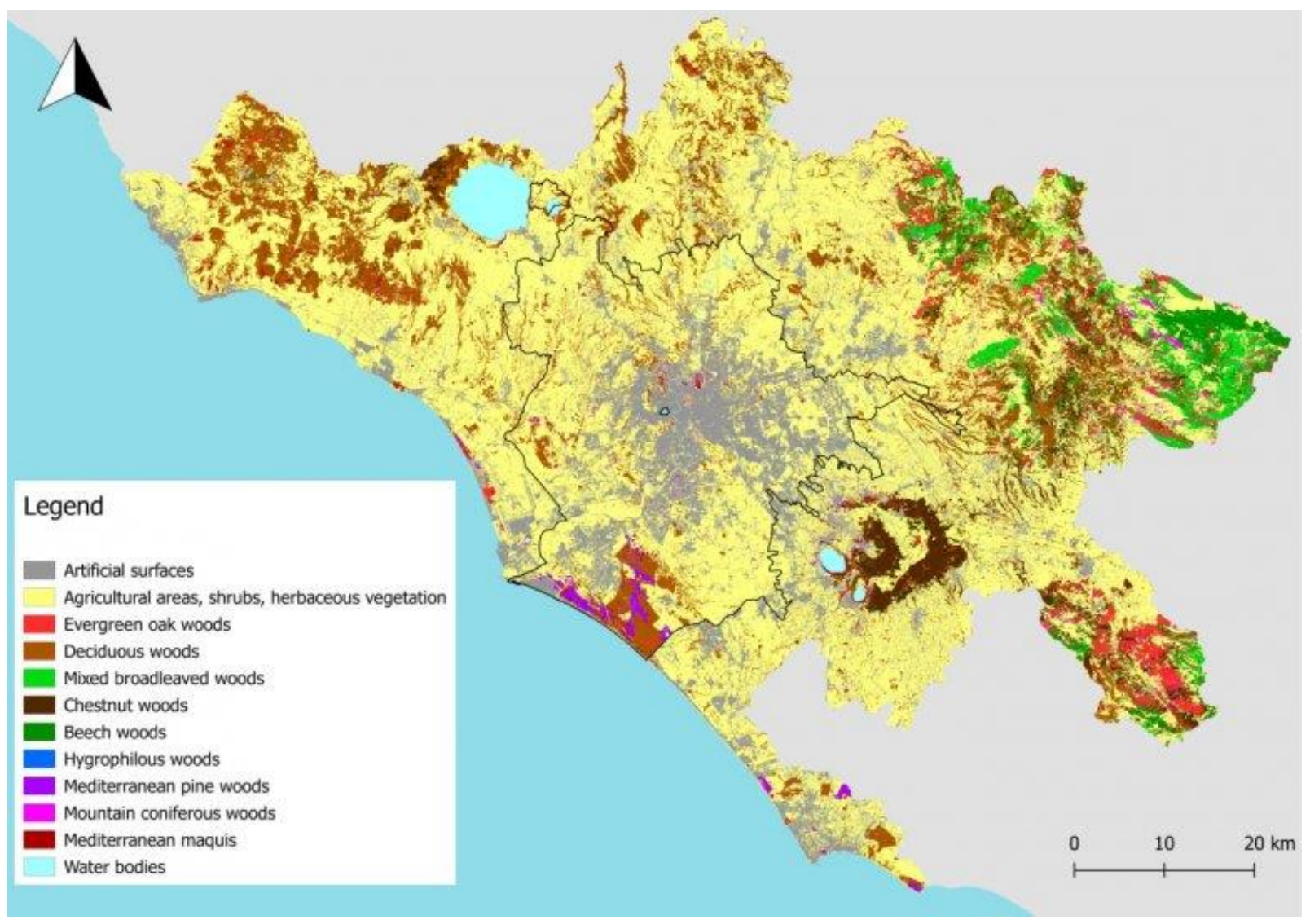

Figure 3. Rome is the largest agri-metropolis in the world with approximately $50 \%$ still developed with agricultural activities (Source: Fusaro et al., 2017)

The actual urban and land planning of the city of Rome is, thus, highly complex and impacted by several diverse regulations that intersect the human and public, archeological, and cultural, landscape and forest, blue and green spaces. Nevertheless, the built areas - born in times where this knowledge and related protection measures were not available - are highly affected by (or affecting) natural and cultural resources and risks. The citizens and stakeholders are mostly unaware of the complex, challenging and risky conditions that characterize the urban ecosystem they live in. Competing social and economic sectors often lack cooperation and there are no fair and safe management plans for allocating natural resources, public and private spaces. The actual and next generation challenge for the city of Rome lies in the multiple facets and interfaces that govern the urban landscape. Major opportunities are, nowadays arising from financial support linked to the ecologic and digital transformation that is majorly supporting green actions and transformations such as Nature Based Solutions (NBS) to mitigate environmental, hydro-meteorological, and climatic risks. This is a major challenge for the city of Rome that seems to have limited and constrained space to accommodate the green and blue protection and innovation measures. As a result, proper knowledge and 
management of these inter-linked components may support safely and sustainable urban planning where the citizen is the engaged in all stages of the decision-making process. We envision here the adoption of Nexus principles that link these interfaces starting from the human-water interface, that was the specific subject of the water resources and risk management plans, towards enlarged approaches that move towards the mainstreaming of the Water-Energy-Food-Ecosystem Nexus.

This work presents, thus, the city of Rome case study with specific focus on the value and the need of embracing the green economy principles, approaches and technologies with citizen-centered approaches and vision that embraces WEFE Nexus principles and approaches for increasing the safety and resiliency of the city to pressing socio-demographic, economic, cultural and climate changes.

\section{A citizen-centered city resilience model for the co-creation of the urban space supporting the urban and green transformations}

Resiliency is a multi-faceted challenge where diverse multiple components are mutually interfacing within living urban spaces. Here we envision a citizen-centred bottom-up model where citizens and stakeholders are engaged and involved in all phases of the knowledge production and sharing towards a participatory decision-making process. We posit participatory models are key for rapidly transforming urban spaces called to embrace in short time, within complex spaces, novel digital and ecologic transition processes.

We introduce a simple schematic to depict this principle that is represented in Figure 4.

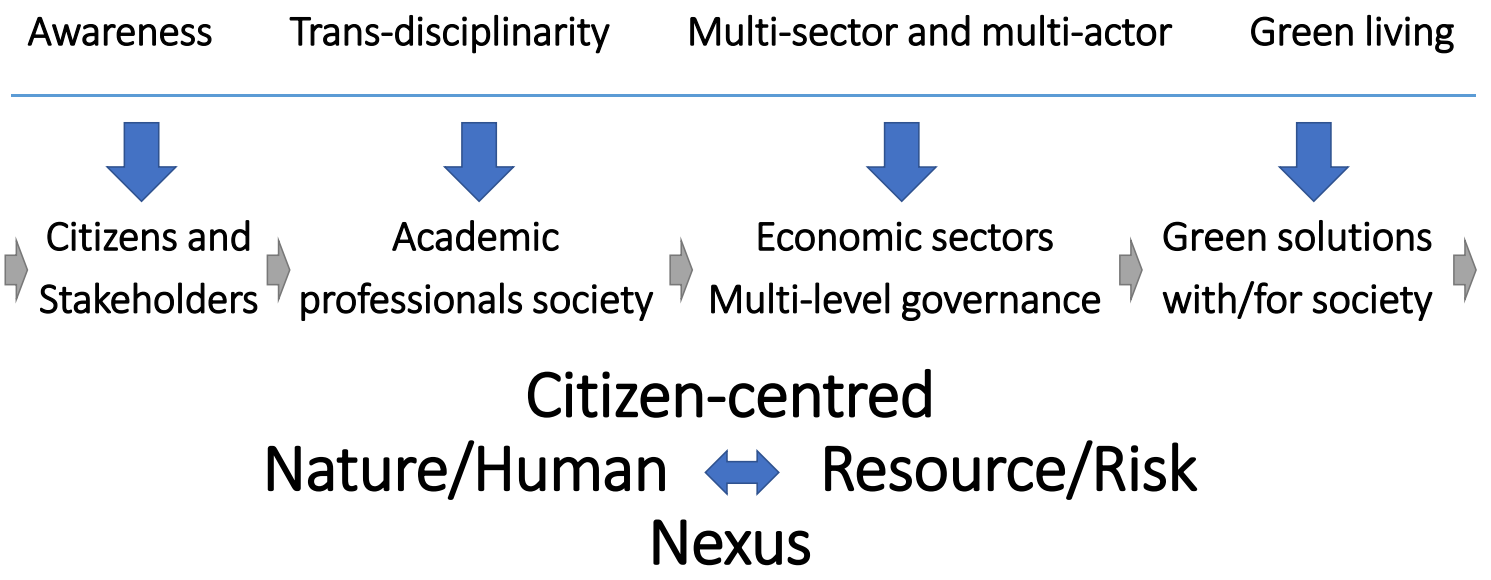

Figure 4. Awareness, Trans-disciplinarity, Multi-sector and Multi-Actor and Green Economy: the four major components of the proposed co-creation urban transformative process.

Four main components are identified and represented to form an iterative co-creation cycle that support participatory knowledge and decision-making process:

Awareness: Everyone must be aware of the issues and the solutions. Citizens are not always aware of the problems that affect the ecosystem they live in. Often the visible (e.g., pollution, urban décor, traffic) is largely overestimated as respect to the invisible, but well-known impacting factors like natural hazards (e.g., floods, landslides, etc.). At the same time the solutions may be ready to be used and implemented, but there are no top-down prompt actions by governing bodies as well as there is no consensus on the urgency of the available solutions. The missed awareness, knowledge on these solutions drive the lack of interest by the 
governors. When these natural and human-driven hazards occur, then, social and economic damages are relevant.

Trans-disciplinarity: There is no one-discipline solution to urban challenges. All knowledge sectors, practitioners shall cooperate, and the collaboration shall work across academic and professional disciplines as well as engaging society (citizens and stakeholders). Only a full trans-disciplinary joint effort may support the co-identification of the optimal solution to pressing diverse issues that affect our urban ecosystems.

Multi-sector and multi-actor: Social and economic segmentation is a major challenge for moving towards more resilient cities. All interested (and often competing) economic sectors and actors (governors, citizens, stakeholders, users etc.) shall cooperate for fair and sustainable use and development of both common and private spaces.

Green living: Fair safe and green living (labs) are needed to test the co-creation process of urban development and transformations. The embracing of living labs and participatory models is fundamental to investigate and identify optimal working models to support urban transition towards increased resiliency. The embracing of bottom-up approaches is, thus, here recognized as fundamental asset for greener and safer living.

This participatory model recognizes the importance of understanding and managing the interlinking of all the components. As a result, Nexus principles and approaches, are needed for sustaining the proposed citizencentred approach where it is recognized that for valuing natural there is strict interlink with the human footprint. Analogously, for valuing natural resources there needs to recognize the related risk (for example abundance of water resources often implies the presence of flood risk) and for valuing.

\section{The City of Rome case study: the urban planning changing dynamics linked to novel landscape and water resources and risk management plans}

The major regional and city planning tools are represented by the Regional Spatial Landscape Plans (Piano Territoriale Paesaggistico Regionale - PTPR), Hydrogeological Planning namely the Floods and Landslide Risk Management Plans (Piano di Assesto Idrogeologico - PAl) and City of Rome General Regulatory Plans (Piano Regolatore Generale - PRG) adopted at municipal level (see Figure 5). Those land and urban planning instruments, deriving from a diverse set of European Directives, National and Regional laws, act at different spatial and temporal scales. This section briefly and schematically depicts the above-mentioned plans to support the understanding of the novel regional planning that characterize the city of Rome as related to the specific integration of the recent river basin scale plans (PAI). In other words, specific interest of this work is to investigate the changing urban planning dynamics as related to the absorption of the knowledge (and, thus, the protection) of the natural resources and risks derived from fluvial and hillslope ecologic, geomorphic and hydrologic-hydraulic modelling zoning (see Spasiano and Nardi, 2019).

The flood and landslide zoning, together with the ecological protection measures, resulting from the technical norms of the above-mentioned plans, are defining a novel urban and land planning regime. Novel norms embrace the green economy paradigms. One notable example is represented by the "zero hydrologic impact" or "hydraulic invariance" norm that imposes any urban transformation plan to compensate paved surface with water and green measures in order to maintain the same timing and volume of surface runoff in occasion of intense rainfall events. The riparian corridor ecologic protection measures, further, impose the respect of the surface-underground water flux continuity to foster the protection of the ecosystem value of the hyporheic water exchange supporting green and animal life, also within urbanized areas, along riparian corridors. 

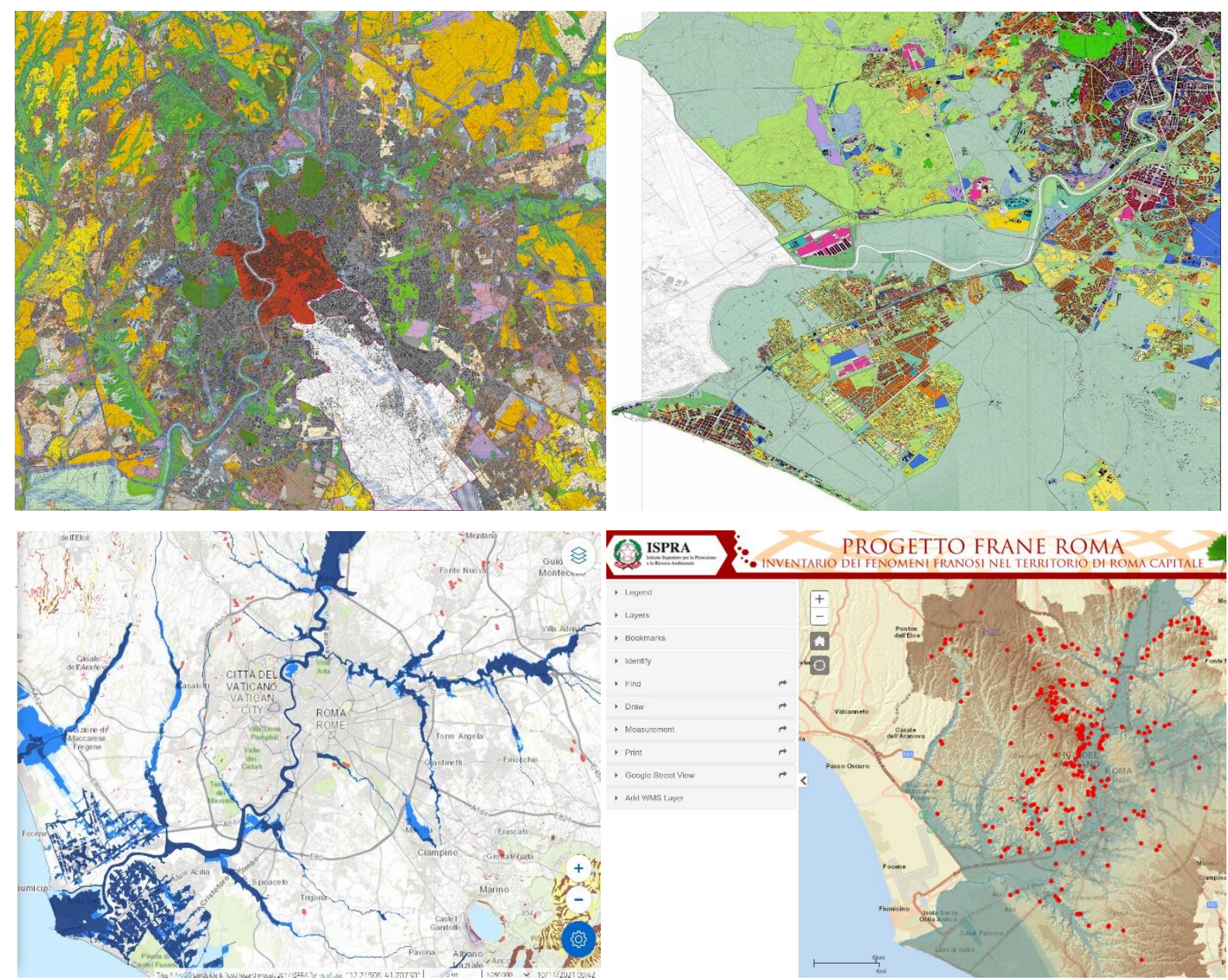

Figure 5. Regional Spatial Landscape Plans (PTPR, top left), City of Rome General Regulatory Plans (PRG, top right), Floods (bottom left, source, ABTevere) and Landslide (bottom right, Source: ISPRA) Risk Management Plans (PAI).

\section{The city of Rome urban and land planning major challenges}

The city of Rome, as a complex urban ecosystem laying on historical natural and cultural heritage, while undergoing to rapid sociodemographic and economic change fostered by the digital and ecologic transition, is having hard times in preserving its historical legacy and, at the same time, guaranteeing safe and sustainable development for citizens and corporations. Several diverse tradeoffs between resources and risks as well as overlapping policies and interests among the sectors and actors involved into the wide decisionmaking chain. The major challenges, as related to the subject of this work, are the following:

- $\quad$ Citizens and stakeholders are not properly informed and involved (especially for natural hazards) resulting in lack of awareness of the issues and the potential solutions.

- Wide range of governing bodies and economic sectors that do not work cooperatively for the management, use and development of natural, urban and cultural resources and risks resulting in overlapping, inefficiency and misleading policy and decision making.

- $\quad$ Lack of synergies among sectors and actors that compete rather than cooperate for fair and safe access to resources. 
- Digital and ecological (green) transitions are seen as top-down enforcements rather than an opportunity for a more resilient and prosperous society.

\section{The way forward: citizen engagement and the mainstreaming of Nexus services for green transition}

The presented case study envisions the implementation of novel procedures that foster citizen engagement and Nexus approaches effectively supporting the co-design and validation of green ecosystem services for managing resources and mitigating natural and human-driven hazards.

The envisioned procedures are citizen-centered not only for the desired co-creation of knowledge production and participatory decision-making processes, but citizens are integrated into new monitoring and proactive community-based processes that seek to include human-derived observations and behaviors. Citizen engagement serves, as a result, as key assets for creating a community of engaged practitioners supporting trans-disciplinary approaches that connect the diverse academic and professional fields interested into the urban planning actions. Citizens and stakeholders allow to also break barriers across the wide range of economic and professional sectors paving the way for fair and effective multi-sector and multi-actor cooperation (Spasiano et al., 2021a). Novel participatory methods and crowdsourcing are also seen as optimal means for the conceptualization of novel urban and land management practices. A schematic of the potential use of citizen science and crowdsourcing is represented in Figure 6 extracted from Nardi et al. (2021).

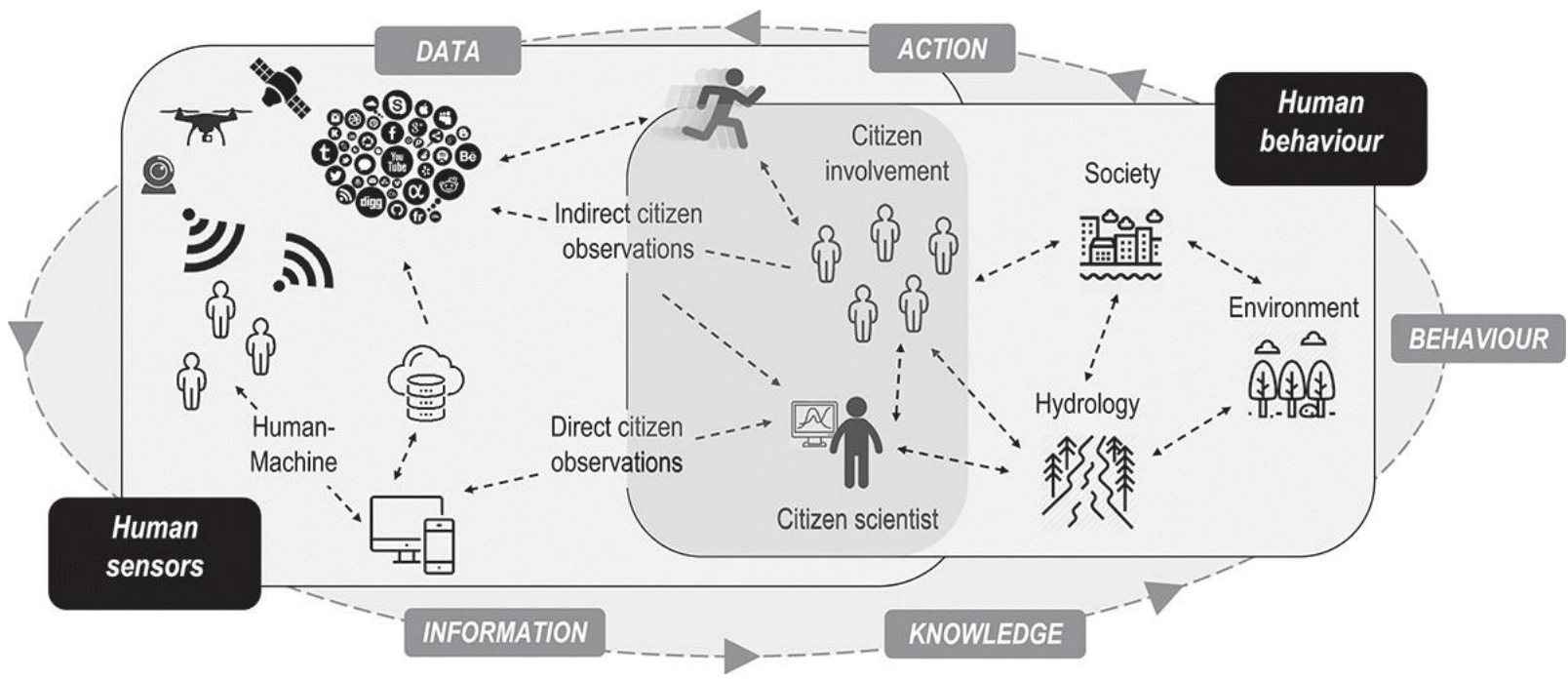

Figure 6. Citizens engaged as human sensors and human behaviour components of a novel data-actionbehaviour-information-knowledge interactive process promoting citizen science (Nardi et al., 2021).

The mainstreaming of Nexus approaches is the further key asset for addressing the major challenges depicted in the previous section. Here, for Nexus approaches, we refer to knowledge, measures and actions, specifically related to urban and land management, that always take into consideration both all physical, environmental and societal components. A notable example is represented by the joint consideration of natural resources with specific regard to water, energy, food and environmental resources, namely the WEFE Nexus (Biggs et al., 2015; D'Odorico et al., 2018).

Fair and safe access to resources shall, thus, be guaranteed by the adoption of Nexus approaches. We introduce, here, the co-design of an organized set of actions that transfer Nexus approaches and procedures 
into real world practice for all actors and users, namely Nexus services. Nexus services shall be design using participatory approaches with stakeholders and citizens that must cooperate in the co-creation of Nexusoriented knowledge sharing and decision-making dynamics specifically oriented for water, land and urban management. The ongoing EU-funded (PRIMA Med) NEXUS-NESS project will work in this direction by cocreating and co-validating in four Living Labs (in four Euro-Med sites in Italy, Spain, Tunisia and Egypt) a Nexus services to address major challenges co-identified with local and regional actors. The city of Rome case study was selected as co-demonstrator case in the validation of the Nexus-Ness solution in the last exploitation phase of the project. A schematic of the procedure, extracted from the Nexus-Ness workplan, is inserted in Figure 7.

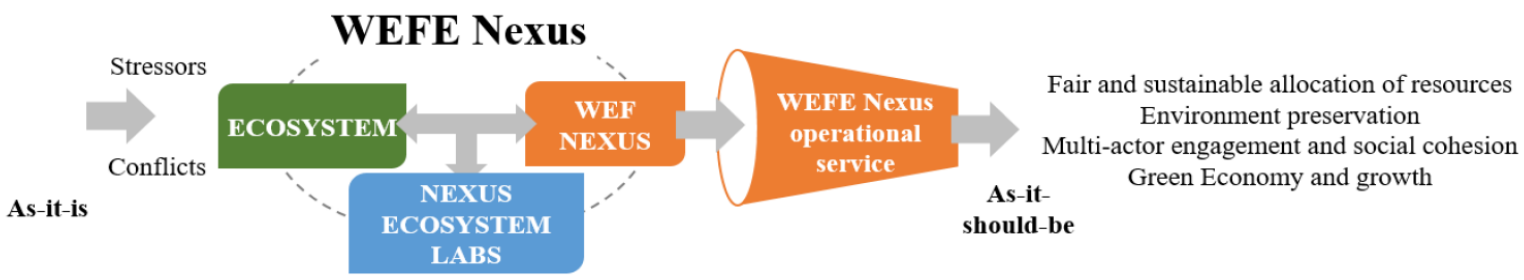

Figure 7. The Nexus-Ness service conceptual framework for transitioning to Nexus-oriented approaches for safe and fair use of natural resources.
A complex valuable \& vulnerable natural \& historical urban ecosystem
- Abundance natural \& cultural resources
$\leftrightarrow \rightarrow$ Human-driven \& Natural hazards
- Competing \& synergic economic sectors
$\leftarrow$ Agriculture \& Industry/Urban
- Safety \& Protection \& Development
$\leftarrow$ Fair/Open \& Growth
- Technical solutions \& Culture
$\leftarrow \rightarrow$ Green economy opportunities \& Barriers
- Digital \& Energy/Climate transition
$\leftarrow$ Social \& Cultural inequities/disparities

WATER

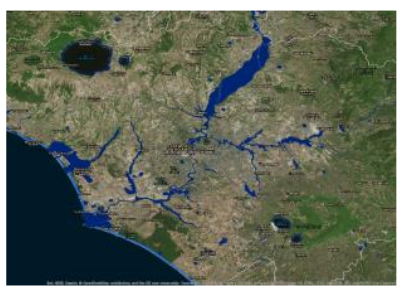

ARCHEOLOGY

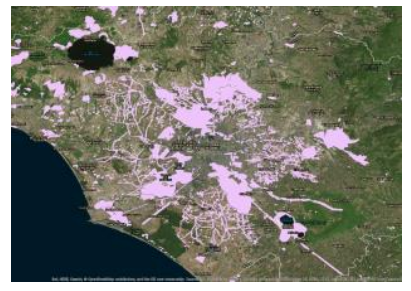

LANDSCAPE HERITAGE

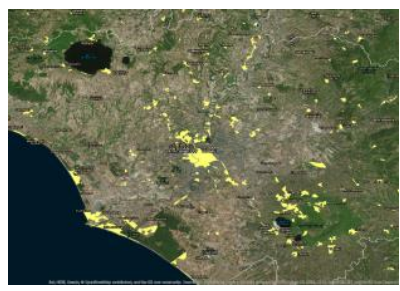

GREEN

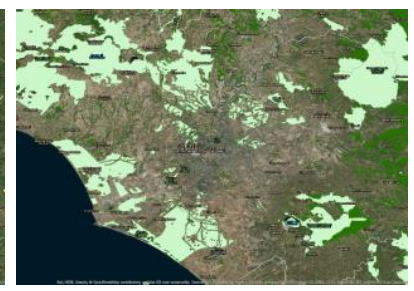

Figure 7. A novel Nexus vision where multiple synergies and trade-offs are jointly considered as interacting and inter-dependent facets of the same urban ecosystem (top table). The bottom section of the figure reports the schematization of the four main components/layers of the urban and land management plans (adapted from Spasiano et al., 2021b). 


\section{Green measures for addressing water and food security: insights into nature-based solutions for the city of Rome}

The selected approach, integrating citizen engagement and Nexus approaches, is selected as a suitable means for supporting the green transition for increased resilience, climate adaptation and hydrometeorological risk mitigation for the city of Rome. Nature Based Solutions (NBS) are sought to be the most proper technologies for serving the city urban and land planning actions while effectively considering the multiple and complex facets of the city, with specific regard to the need of preserving the cultural and green spaces while not slowing down the socio-demographic and economic pressures.

The ongoing NBS include blue and green roofs that are being tested for their capability of flood risk management and infrastructure (e.g., sewers) increased efficienty as well as for the indoor-outdoor temperature control that mitigate climate-driven issues (e.g., heat islands in urban centers). Additionally, green roofs support the development of urban agriculture. This green technology has multiple benefits, from public and citizen engagement for increased awareness on the value and need of such green actions for the city safety and resilience as well as for mainstreaming Nexus services linked to local WEFE (water-energyfood-ecosystem) resource optimal management. In Figure 8 a selection of green technologies that include: the co-testing of Polder Roofs (by MetroPolder company, the Netherlands, a Climatic KIC funded project coordinated by TU Delft with WARREDOC center at University for Foreigners of Perugia as sub-coordinating unit for the network of four Italian demonstration sites) and the urban agriculture scientific and practical studies (Polytechnic of Milan POLIMI, WP leader for Nexus-Ness for WEFE Nexus services).

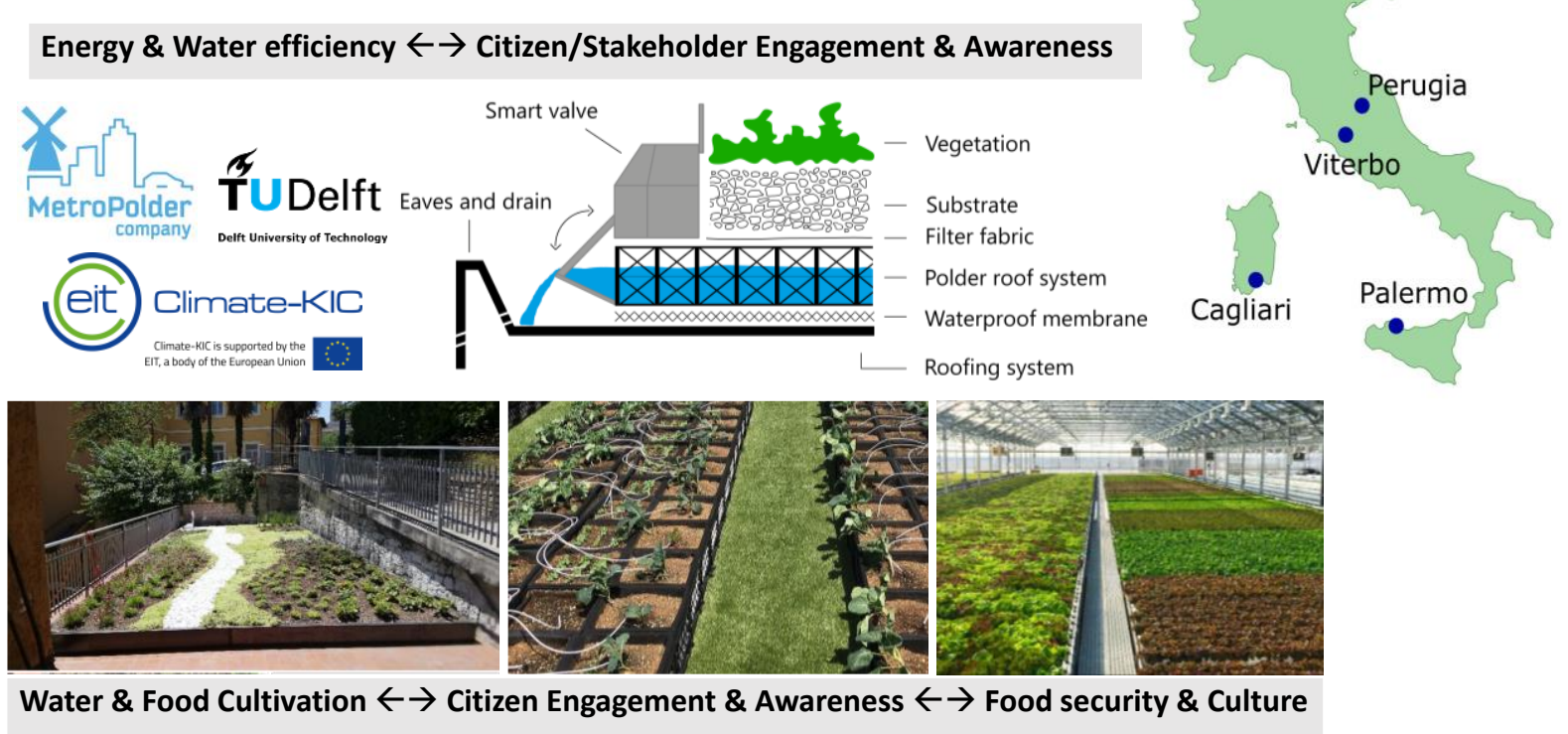

Figure 8. Green roofs for climate, water and food security towards increased resilience of urban ecosystems. A schematic representation of ongoing actions and projects related to the selected Italian case studies: the Polder Roof blue-green tech by Metro Polder company within the EU-funded TU Delft project in collaboration with WARREDOC coordinating the four test sites in Italy; bottom right, the Polder Roof in Perugia; Bottom Center-Right: Urban agriculture sample technologies by Politecnico di Milano - POLIMI). 


\section{References}

Biggs, E. M., Bruce, E., Boruff, B., Duncan, J. M., Horsley, J., Pauli, N., ... \& Imanari, Y. (2015). Sustainable development and the water-energy-food nexus: A perspective on livelihoods. Environmental Science \& Policy, 54, 389-397.

D'Odorico, P., Davis, K. F., Rosa, L., Carr, J. A., Chiarelli, D., Dell'Angelo, J., ... \& Rulli, M. C. (2018). The global food-energy-water nexus. Reviews of geophysics, 56(3), 456-531.

Fusaro, L., Marando, F., Sebastiani, A., Capotorti, G., Blasi, C., Copiz, R., ... \& Manes, F. (2017). Mapping and Assessment of PM10 and 03 Removal by Woody Vegetation at Urban and Regional Level. Remote Sensing, 9(8), 791.

Nardi, F. et al. (2021) 'Citizens AND HYdrology (CANDHY): conceptualizing a transdisciplinary framework for citizen science addressing hydrological challenges', Hydrological Sciences Journal, 00(00), pp. 1-18. doi: 10.1080/02626667.2020.1849707.

Regione Lazio (2007), 'Piano Paesistico Territoriale Regionale-Relazione'

Spasiano, A. and Nardi, F. (2019) 'A GIS-based fuzzy analysis for mapping the touristic potential in Lazio Region (Italy)', J-Reading - Journal of Research and Didactics in Geography, pp. 41-54. doi: 10.4458/2252-03.

Spasiano, A. et al. (2021a), 'Towards a Transdisciplinary Theoretical Framework of Citizen Science: Results from a Meta-Review Analysis' Sustainability, 13(14), p.7904. doi: http://dx.doi.org/10.3390/su13147904.

Spasiano, A. et al. (2021b), Geospatial data homogenization and processing for integrated assessment of urban and natural resources and risks: A pilot case for Lazio Region (Italy). ISOCARP World Congress proceedings. 